\title{
Stent implantation for coarctation of the aorta in a premature infant through carotid cutdown as a bridge to surgical correction
}

\author{
V. Vivian Dimas, MD, ${ }^{\mathrm{a}}$ Steven R. Leonard, MD, ${ }^{\mathrm{b}}$ Kristine J. Guleserian, MD, ${ }^{\mathrm{b}}$ Joseph M. Forbess, MD, ${ }^{\mathrm{b}}$ and \\ Thomas M. Zellers, MD, ${ }^{\mathrm{a}}$ Dallas, Tex
}

Isolated coarctation of the aorta accounts for $5 \%$ to $10 \%$ of all congenital heart defects. Neonatal repair is typically surgical at our institution. Stent implantation for coarctation is typically reserved for older children in whom a larger-caliber stent can be used that can potentially be postdilated to adult diameters. We report a case of stent implantation for native coarctation as a bridge to successful surgical repair in an extremely preterm infant.

\section{CLINICAL SUMMARY}

The patient was a male infant born at 25 weeks' gestation because of preterm labor. Birth weight was $875 \mathrm{~g}$. After delivery, the patient was noted to have a large patent ductus arteriosus (PDA). He underwent PDA ligation on day of life 6 through a left thoracotomy with multiple clips. After PDA ligation, he had significant upper extremity hypertension. Repeat echocardiographic analysis demonstrated severe aortic coarctation with a Doppler-predicted $58 \mathrm{~mm}$ $\mathrm{Hg}$ gradient. He was transferred to our institution for further care. Echocardiographic analysis at our institution confirmed the diagnosis. The patient remained severely hypertensive, with systolic blood pressures ranging from 97 to $118 \mathrm{~mm} \mathrm{Hg}$ in the upper extremities and 35 to $47 \mathrm{~mm} \mathrm{Hg}$ in the lower extremities with evidence of end-organ hypoperfusion.

A carotid cutdown was performed in the cardiac catheterization laboratory, and a $4 \mathrm{~F}$ sheath was placed in the right internal carotid artery. Angiographic analysis revealed a discrete coarctation adjacent to the ductal clips (Figure 1). The transverse aortic arch measured $3.5 \mathrm{~mm}$, narrowing to 1.04 $\mathrm{mm}$ in the region of the coarctation. The descending aorta distal to the coarctation measured $4.22 \mathrm{~mm}$. Under fluoroscopic guidance, a Vision multi-link $4 \mathrm{~mm} \times 8 \mathrm{~mm}$ premounted coronary stent (Abbott Vascular, Abbott Park, Ill) was used to stent the coarctation segment (Figure 2). There was a trivial residual gradient of 3 to $4 \mathrm{~mm} \mathrm{Hg}$ documented by direct pressure pullback. The cutdown was repaired primarily, and the patient was transferred to the

From the Division of Cardiology, Department of Pediatrics, ${ }^{\mathrm{a}}$ and the Division of Pediatric Cardiothoracic Surgery, Department of Cardiothoracic Surgery, ${ }^{\mathrm{b}}$ University of Texas Southwestern Medical Center Dallas, Dallas, Tex.

Disclosures: None.

Received for publication Aug 6, 2008; revisions received Sept 25, 2008; accepted for publication Oct 13, 2008; available ahead of print April 13, 2009.

Address for reprints: V. Vivian Dimas, MD, Children's Medical Center of Dallas, Division of Cardiology, 1935 Motor St, Dallas, TX 75235 (E-mail: Vivian. dimas@childrens.com).

J Thorac Cardiovasc Surg 2010;139:1070-1

$0022-5223 / \$ 36.00$

Copyright (c) 2010 by The American Association for Thoracic Surgery

doi:10.1016/j.jtcvs.2008.10.055

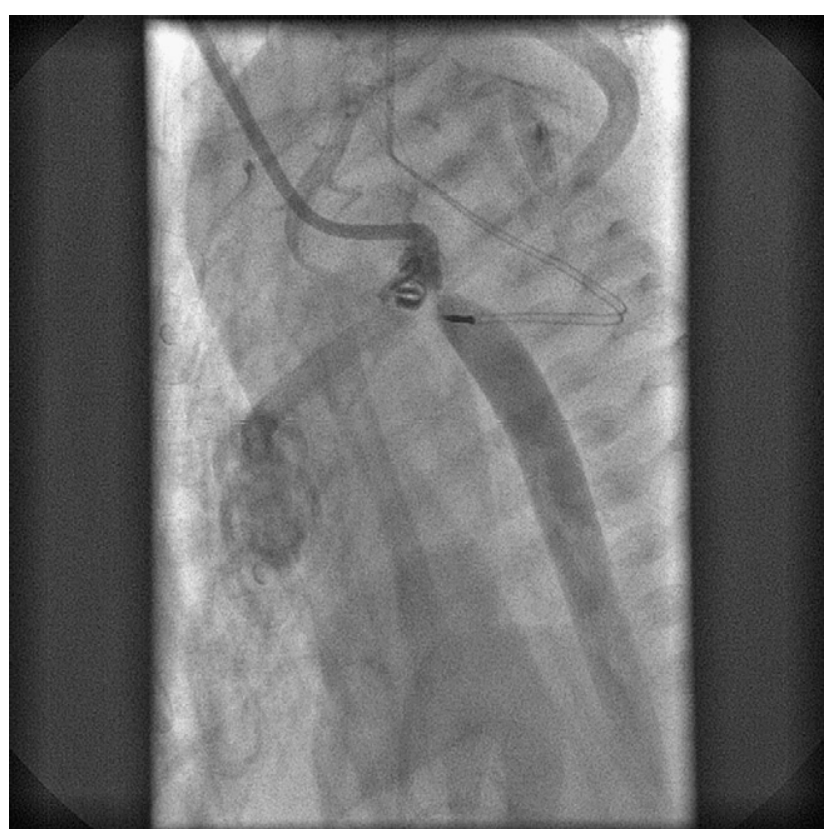

FIGURE 1. The area of discrete coarctation can be visualized adjacent to the ductal clips.

cardiovascular intensive care unit. He was transferred to the referring institution 6 days later and discharged home 3 months after delivery.

He returned at 6 months of age, weighing $5.38 \mathrm{~kg}$, for planned stent removal and definitive coarctation repair. There was a $25 \mathrm{~mm} \mathrm{Hg}$ noninvasive blood pressure gradient, likely caused by somatic growth. The following day, he underwent aortic stent excision and an end-to-end anastomosis with subclavian flap arch augmentation through repeat left thoracotomy. It did not appear that the PDA clips were responsible for the aortic obstruction. Upper and lower extremity blood pressures were equal in the operating room and on discharge on postoperative day 3. He continues to do well and is developmentally appropriate for age at 18 months' follow-up.

\section{DISCUSSION}

Stent implantation for aortic coarctation is rapidly gaining acceptance as an approach in older patients because of short postprocedure recovery periods and relatively low procedural risk. ${ }^{1}$ In younger infants and neonates, surgical repair remains the standard treatment. Repair of coarctation of the aorta in preterm infants is associated with higher rates of recurrent arch obstruction, reported to be as high as $16 \%$ to $29 \%{ }^{2,3}$ Prematurity has been identified as a risk factor for recurrent coarctation, despite 


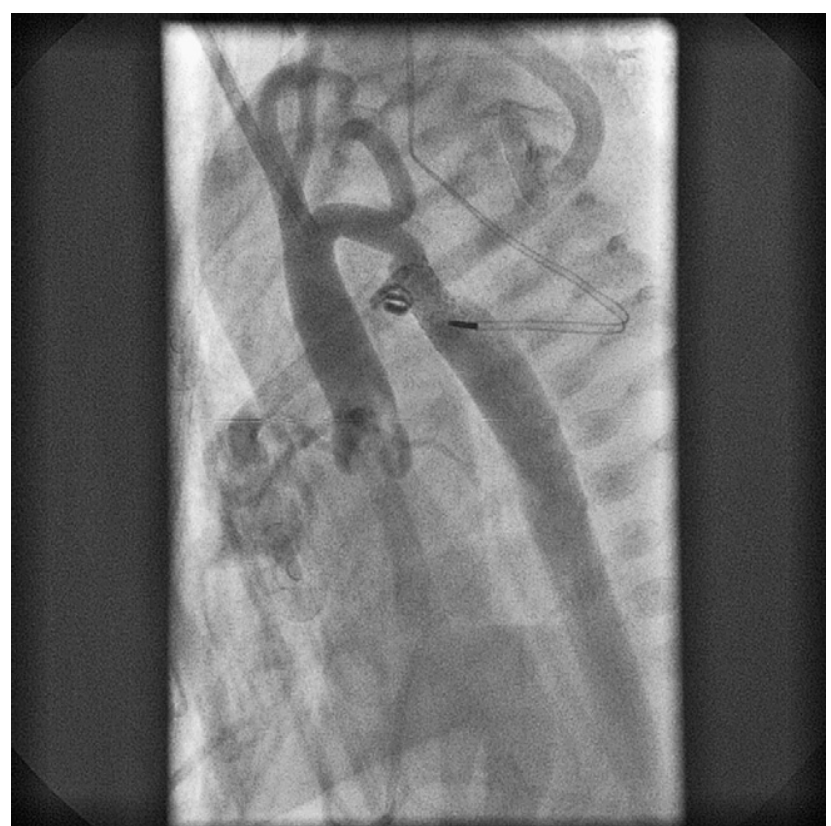

FIGURE 2. Angiogram after stent implantation demonstrating resolution of coarctation.

repair by means of resection with an extended end-to-end anastomosis. 4 We chose a staged hybrid approach with stent implantation for short-term repair of the coarctation, enabling us to stabilize the infant's blood pressure and improve end-organ perfusion. Given concerns over aortic disruption during stent implantation, the stent was inflated to a diameter not exceeding that of the native aorta. Additionally, we selected a short stent to allow for complete excision of the stent-containing aortic segment at the time of coarctation repair.
This case highlights the pitfalls associated with limited evaluation of preterm infants for ligation or medical treatment of what is typically assumed to be an isolated PDA. It also highlights that a collaborative approach with lowrisk therapy as a bridge can result in a highly successful outcome. Palliation in extremely preterm infants has typically been balloon angioplasty, with isolated reports of stent implantation in 3 preterm infants weighing more than $1 \mathrm{~kg}$ and infants of greater than 30 weeks gestation. ${ }^{6-9}$ To our knowledge, this is the first report of stent dilation of coarctation as primary treatment in a 28 -week 800 -g neonate. In our case stent implantation with a low-profile, premounted coronary stent proved to be a safe approach as a bridge to definitive repair and might be applicable in other selected patients.

\section{References}

1. Hornung TS, Benson LN, McLaughlin PR. Interventions for aortic coarctation. Cardiol Rev. 2002;10:139-48.

2. Sudarshan CD, Cochrane AD, Jun AH, Soto R, Brizard CP. Repair of coarctation of the aorta in infants weighing less than 2 kilograms. Ann Thorac Surg. 2006;82: 158-63.

3. Puchalski MD, Williams RV, Hawkins JA, Minich LL, Tani LY. Follow-up of aortic coarctation repair in neonates. $J$ Am Coll Cardiol. 2004;44:188-91.

4. Thomson JDR, Mulpur A, Guerrero R, Nagy Z, Gibbs JL, Watterson KG. Outcome after extended arch repair for aortic coarctation. Heart. 2006;92:90-4.

5. Bacha EA, Almodovar M, Wessel DL, Zurakowski D, Mayer JE, Jonas RA, et al. Surgery for coarctation of the aorta in infants weighing less than $2 \mathrm{~kg}$. Ann Thorac Surg. 2001;71:1260-4

6. Sutton N, Lock JE, Geggel RL. Cardiac catheterization in infants weighing less than 1,500 grams. Catheter Cardiovasc Interv. 2006;68:948-56.

7. Shamberger MA, Lababidi ZA. Successful balloon angioplasty of a coarctation in an infant <500 g. Pediatr Cardiol. 1998;19:418-9.

8. McMahon CJ, Alromani A, Nihill MR. Balloon angioplasty of critical coarctation in a 970-gram premature infant. Cardiol Young. 2001;11:468-71.

9. Radtke WA, Waller R, Hebra A, Bradley SM. Palliative stent implantation for aortic coarctation in premature infants weighting $<1,500$ g. Am J Cardiol. 2002;90:1409-12.

\title{
Innovative surgical technique of right upper bilobe transplantation
}

\author{
Federico Rea, MD, Abdel-Mohsen Hamad, MD, Monica Loy, MD, Cristiano Breda, MD, \\ Marco Schiavon, MD, and Giuseppe Marulli, MD, Padova, Italy
}

Thoracic surgeons involved in lung transplantation are faced with the problems of scarcity of available donors

\footnotetext{
From the Department of Cardiothoracic and Vascular Sciences, University of Padova, Padova, Italy.

Disclosures: None.

Received for publication Jan 28, 2009; accepted for publication April 11, 2009; available ahead of print June 1, 2009.

Address for reprints: Federico Rea, MD, Department of Cardiothoracic and Vascular Sciences, University of Padova, Via Giustiniani, 2, 35128, Padova, Italy (E-mail: federico.rea@unipd.it).

J Thorac Cardiovasc Surg 2010;139:1071-3

$0022-5223 / \$ 36.00$

Copyright (c) 2010 by The American Association for Thoracic Surgery

doi:10.1016/j.jtcvs.2009.04.008
}

and size mismatch between the donor lung and the recipient thoracic cage. Different size-reduction techniques or resection of localized pathology limited to 1 lobe allows tailoring of the grafted lung to the size of the thoracic cage and increasing the donor pool. ${ }^{1}$ We present an innovative technique of size reduction by a right lower lobectomy with the creation of a single bronchial stump for anastomosis.

\section{CLINICAL SUMMARY}

Double-lung transplantation was planned for a 63 -yearold woman with idiopathic pulmonary fibrosis. The matched donor was in a car accident and had a contusion of the right 